\title{
Drug delivery system based on cyclodextrin-naproxen inclusion complex incorporated in electrospun polycaprolactone nanofibers
}

\author{
M. Fatih Canbolat ${ }^{\mathrm{a}, \mathrm{c}, * *}$, Asli Celebioglu ${ }^{\mathrm{a}, \mathrm{b}}$, Tamer Uyar ${ }^{\mathrm{a}, \mathrm{b}, *}$ \\ a UNAM-National Nanotechnology Research Center, Bilkent University, Ankara 06800, Turkey \\ ${ }^{\mathrm{b}}$ Institute of Materials Science \& Nanotechnology, Bilkent University, Ankara 06800, Turkey \\ c Suleyman Demirel University, Engineering Faculty, Textile Engineering, Isparta 32260, Turkey
}

\section{A R T I C L E I N F O}

\section{Article history:}

Received 4 July 2013

Received in revised form 9 November 2013

Accepted 11 November 2013

Available online 19 November 2013

\section{Keywords:}

Nanofibers

Drug

Cyclodextrin

Inclusion complex

Naproxen

Release

\begin{abstract}
A B S T R A C T
In this study, we select naproxen (NAP) as a reference drug and electrospun poly ( $\varepsilon$-caprolactone) $(\mathrm{PCL})$ nanofibers as a fibrous matrix for our drug-delivery system. NAP was complexed with betacyclodextrin $(\beta C D)$ to form inclusion complex (NAP- $\beta C D-I C)$ and then NAP- $\beta C D-I C$ was incorporated into PCL nanofibers via electrospinning. The incorporation of NAP without CD-IC into electrospun PCL was also carried out for a comparative study. Our aim is to analyze the release profiles of NAP from PCL/NAP and PCL/NAP- $\beta C D-I C$ nanofibers and we investigate the effect of CD-IC on the release behavior of NAP from the nanofibrous PCL matrix. The characterization of NAP- $\beta C D-I C$ and the presence of CD-IC in PCL/NAP- $\beta C D-I C$ nanofibers were studied by FTIR, XRD, TGA, NMR and SEM. The SEM imaging of the electrospun PCL/NAP and PCL/NAP- $\beta C D$-IC nanofibers reveal that the average fiber diameter of these nanofibers is around $300 \mathrm{~nm}$, in addition, the aggregates of CD-IC in PCL/NAP- $\beta C D-I C$ nanofibers is observed. The release study of NAP in buffer solution elucidate that the PCL/NAP- $\beta C D-I C$ nanofibers have higher release amount of NAP than the PCL/NAP nanofibers due to the solubility enhancement of NAP by CD-IC.
\end{abstract}

(C) 2013 Elsevier B.V. All rights reserved.

\section{Introduction}

The main function of drug delivery systems is to transport various drugs to the target sites in the body in a secure way and adjust the release mechanisms by controlling the amount of drugs and treatment time $[1,2]$. There are several carriers and formulations used for drug delivery purposes such as polymeric matrices, gels, cyclodextrins, liposomes, microspheres, foams, films and some others [3-8]. In drug delivery, it is expected from a carrier material to have at least following properties; biocompatibility, non-toxicity, lack of immunogenicity, acceptable biodegradation time, reproducibility, and continuous activation till arrival to the target $[9,10]$.

Nanostructures and cyclodextrins (CD) present significant opportunities in drug delivery systems with their unique and promising characteristic features. Nanostructures improve the release behavior and stability of the drugs by maintaining the drug

\footnotetext{
* Corresponding author at: UNAM-National Nanotechnology Research Center, Bilkent University, Ankara 06800, Turkey. Tel.: +90 3122903571; fax: +90 3122664365 .

** Corresponding author at: Suleyman Demirel University, Engineering Faculty, Textile Engineering, Isparta 32260, Turkey. Tel.: +90 2462111188; fax: +902462111180 .

E-mail addresses: fatihcanbolat@sdu.edu.tr (M.F. Canbolat), tamer@unam.bilkent.edu.tr (T. Uyar).
}

concentration within a therapeutic window and overcoming the biological barriers for cellular uptake $[11,12]$. On the other hand, CDs induce improvement in drug release profiles and enhancement in drug solubilization and stabilization by forming inclusion complexes (ICs) with drugs $[13,14]$. However, there is no standard or ideal structure available for drug delivery purpose and many studies are reported on developing much better structures for the site specific drug targeting [15-17].

Naproxen (NAP) is a poorly water soluble, non-steroidal antiinflammatory drug (NSAIDs) that is used to relieve pain or inflammation $[18,19]$. Yet, enhanced solubility achievements of naproxen by forming cyclodextrin inclusion complexes (CD-IC) were reported $[20,21]$. Apart from $C D$, the use of electrospun nanofibers as an incorporating matrix also enhanced the release behavior of NAP in comparison with cast films [22]. However, the main function of electrospun nanofibers in drug delivery applications can be defined as their controlled and sustained release behaviors $[23,24]$. In drug delivery field, while there are studies about incorporation of CDs into polymeric structures such as hydrogels and films [25,26], a very limited number of reports are available related to incorporation of $\mathrm{CD}-\mathrm{IC}$ of active agents such as drugs [27], antibacterials [28], essential oils [29] and flavors/fragrances [30-33] into electrospun nanofibers for delivery and stabilization purposes. For instance, using cyclodextrin as a stabilizing and solubilizing agent and electrospun nanofiber mats as a carrier matrix 
for sustained release may open up new pathways for drug delivery purpose based on improved release performance of the drug.

CDs ( $\alpha-, \beta-$, and $\gamma$-types) are cyclic oligosaccharides which are enzymatically converged from starch that comprise glucopyranoside units linked with $\alpha$ (1-4) bonds [34]. CDs are hollow and truncated cone shaped molecules that have hydrophobic cavity and hydrophilic outer shell which enable them to constitute noncovalent host-guest inclusion complexation with variety of molecules in various forms [34,35]. On the other hand, electrospun nanofibers are other promising nanostructures in drug delivery applications [36-38]. There are many reasons for nanofiber structures to be preferred and used in biomedical application areas, i.e., small fiber size, high porosity, interconnected porous structure, and capability to embed various functional additives into them.

In this study, naproxen (NAP) and inclusion complex of naproxen with beta-cyclodextrin (NAP- $\beta C D-I C)$ was incorporated into polycaprolactone (PCL) electrospun nanofibers for our drugdelivery system. We compared the release profiles of NAP from $\mathrm{PCL} / \mathrm{NAP}$ and PCL/NAP- $\beta C D-I C$ nanofibers and we examined the effect of inclusion complexation on the release behavior of NAP from the nanofibrous PCL matrix. In this regard, we first tested the effect of $\beta C D$ on the solubility of NAP by forming inclusion complexation. NAP shows higher solubility in NAP- $\beta C D-I C$ when compared to free NAP which is consistent with the literature $[39,40]$. Parallel to this result, improved release profile of NAP from PCL/NAP- $\beta C D-$ IC nanofibers is observed, as well.

\section{Experimental}

\subsection{Materials}

Naproxen (NAP) was commercially purchased from Abdi Ibrahim Pharmaceutical Company (Turkey). Polycaprolactone (PCL) $\left(M_{\mathrm{W}}: 80,000\right.$, Sigma Aldrich), N,N-dimethylformamide (DMF) (Riedel, Pestanal), dicholoromethane (DCM) (Sigma, Extra Pure), and potassium dihydrogen phosphate (VWR, Chromanorm for HPLC) were obtained commercially from various suppliers. Betacyclodextrin $(\beta C D)$ was obtained from Wacker Chemie AG (Germany) and the de-ionized water was obtained from the Millipore Milli-Q Ultrapure Water System. All materials were used without any purification.

\subsection{The preparation of solid $\beta C D-N A P$ inclusion complex $(N A P-\beta C D-I C)$}

For the NAP- $\beta C D$-IC formation, $1 \mathrm{~g}$ of $\beta C D$ was dissolved in $18 \mathrm{ml}$ water and $250 \mathrm{mg}$ NAP was dispersed in $2 \mathrm{ml}$ water, separately. Then, the NAP solution was added into CD solution slowly. Ultimate solution was stirred over-night and a turbid dispersion was obtained. It was kept at $-80^{\circ} \mathrm{C}$ and freeze-dried to obtain NAP$\beta C D-I C$ powder.

\subsection{The preparation of electrospinning solutions}

The NAP- $\beta C D-I C$ including PCL solution was obtained by dispersing the NAP- $\beta C D-I C$ powder in clear and homogenous PCL $(15 \%$ $(\mathrm{w} / \mathrm{v})$, with respect to solvent) $\mathrm{DMF} / \mathrm{DCM}(3: 1, \mathrm{v} / \mathrm{v})$ solution, at the $20 \%(\mathrm{w} / \mathrm{w})$ polymer concentration. For comparison, the pure PCL $(15 \%, \mathrm{w} / \mathrm{v})$ and only NAP including $(4 \%(\mathrm{w} / \mathrm{w})$ with respect to polymer concentration) PCL $(15 \%, \mathrm{w} / \mathrm{v})$ solutions were also prepared in $\operatorname{DMF} / \mathrm{DCM}(3 / 1, \mathrm{v} / \mathrm{v})$ blend system.

\subsection{Electrospinning}

The PCL, PCL/NAP and PCL/NAP- $\beta C D-I C$ solutions were placed in a $3 \mathrm{ml}$ syringe fitted with a metallic needle of $0.6 \mathrm{~mm}$ inner diameter. The syringe was fixed horizontally on the syringe pump (model SP 101IZ, WPI, USA). The positive electrode of the high-voltage power supply (Matsusada Precision, AU Series, Japan) was clamped to the metal needle tip, and the cylindrical aluminum collector was grounded. The parameters of the electrospinning were adjusted as; feed rate of solutions $=1 \mathrm{ml} / \mathrm{h}$, the applied voltage $=15 \mathrm{kV}$, and the tip-to-collector distance $=10 \mathrm{~cm}$. Electrospun nanofibers were deposited on a grounded stationary cylindrical metal collector covered with a piece of aluminum foil. The electrospinning apparatus was enclosed in a Plexiglas box, and electrospinning was carried out at $25^{\circ} \mathrm{C}, 20 \%$ relative humidity. The collected nanofibers were dried at room temperature under the fume hood overnight.

\subsection{Measurements and characterization}

The exact molar ratio between NAP: $\beta C D$ in the inclusion complex was determined by using proton nuclear magnetic resonance $\left({ }^{1} \mathrm{H}\right.$ NMR, Bruker D PX-400) system. The NAP- $\beta C D-I C$ powder was dissolved in d6-DMSO (in $20 \mathrm{~g} / \mathrm{L}$ concentration). The spectra were recorded at $400 \mathrm{MHz}$ and at 16 total scan. A rheometer (Anton Paar Physica CR 301) equipped with a cone/plate accessory (spindle type $\mathrm{CP} 40-2$ ) was used to measure the rheological behavior of PCL, PCL/NAP and PCL/NAP- $3 C D-I C$ solution in the range of 0.1 to 100 1/s shear rate. The scanning electron microscope (SEM) (FEI Quanta 200 FEG) was used for the morphological analysis of the electrospun nanofibers. Samples were sputtered with $5 \mathrm{~nm} \mathrm{Au} / \mathrm{Pd}$ prior to SEM imaging. The average fiber diameter (AFD) was determined from the SEM images, and around 100 fibers were analyzed. The crystalline structure determination of the NAP, $\beta C D$, NAP$\beta C D-I C$ powder and PCL, PCL/NAP and PCL/NAP- $\beta C D-I C$ nanofibers were investigated by using X-ray diffraction (XRD) (PANalytical $X$ 'Pert powder diffractometer) having $\mathrm{Cu} K \alpha$ radiation in a range of $2 \theta=5-30^{\circ}$. The thermal properties of electrospun nanofibers were studied by thermogravimetric analysis (TGA) (TA Q500) and the measurements were carried out from 25 to $500^{\circ} \mathrm{C}$ at $20^{\circ} \mathrm{C} / \mathrm{min}$ heating rate, and $\mathrm{N}_{2}$ was used as a purge gas. The infrared spectra of the nanofibers were obtained by using a Fourier transform infrared spectrometer (FTIR) (Bruker-VERTEX 70). For measurement, the samples were mixed with potassium bromide $(\mathrm{KBr})$ and pressed as pellets. The scans (64 scans) were recorded between $4000 \mathrm{~cm}^{-1}$ and $400 \mathrm{~cm}^{-1}$ at a resolution of $4 \mathrm{~cm}^{-1}$. UV-vis-spectroscopy (Varian Cary 5000) was used to determine the solubility difference between pure NAP and NAP- $\beta C D$-IC. For this purpose, $5 \times 10^{-4} \mathrm{M}$ NAP powder and NAP- $\beta C D-I C$ that includes the same amount of NAP were dissolved in water. After $24 \mathrm{~h}$ stirring, the solutions were filtered and the UV absorbance of samples was measured in the 250-370 $\mathrm{nm}$ range.

\subsection{The NAP release profile from electrospun PCL nanofibers}

The HPLC system (Agilent 1200 Series) was used to investigate the release profiles of PCL/NAP and PCL/NAP- $\beta C D-I C$ nanofibers. The separation of NAP was performed with Zorbax Eclipse XDB-C18 column $(150 \mathrm{~mm} \times 4.6 \mathrm{~mm}, 5 \mu \mathrm{m}$ particle size $)$ and it was detected at $230 \mathrm{~nm}$ wavelength. Acetonitrile $(100 \%)$ was used as mobile phase at a flow rate of $1 \mathrm{ml} / \mathrm{min}$ and the injection volume was kept at $10 \mu \mathrm{l}$. For the test, $30 \mathrm{mg}$ weighted PCL/NAP and PCL/NAP-BCDIC nanofibers were immersed into $30 \mathrm{ml}$ buffer solutions and they were kept in that buffer to determine the released amount of NAP at the progressing time intervals. The experiments were repeated three times for both composite nanofibers. The calibration curve of NAP was prepared by using stock solutions in 7 different concentrations; $20 \mathrm{ppm}, 10 \mathrm{ppm}, 5 \mathrm{ppm}, 2 \mathrm{ppm}, 1 \mathrm{ppm}, 0.5 \mathrm{ppm}$ and $0.2 \mathrm{ppm}$. It showed linearity and acceptability with $R^{2} \geq 0.99$. 
<smiles>COc1ccc2cc([C@H](C)C(=O)O)ccc2c1</smiles>
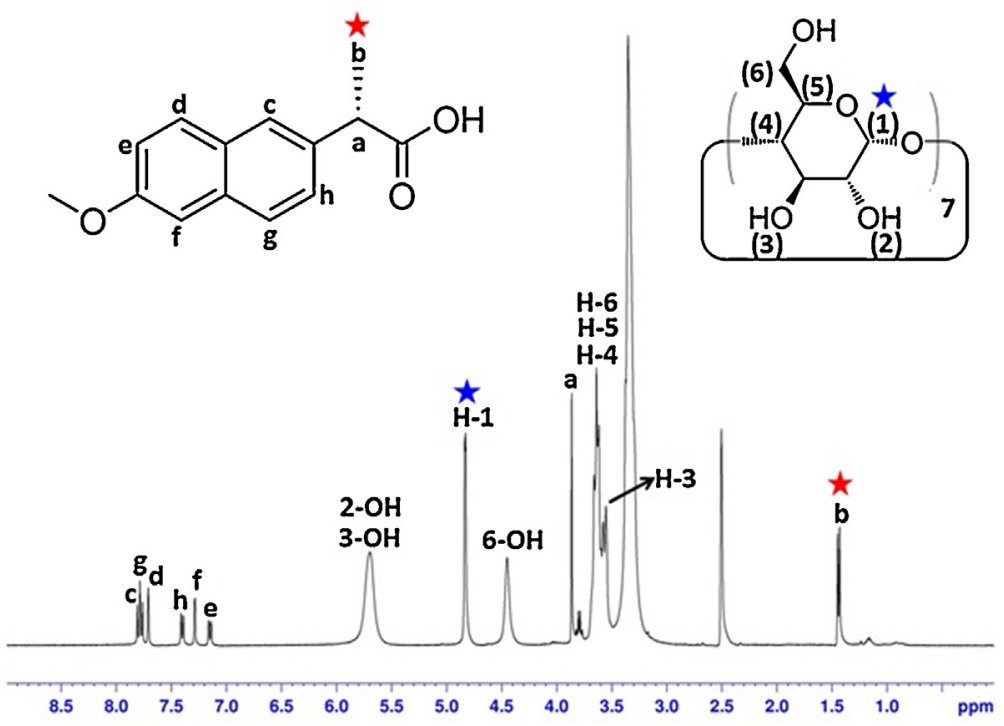

Fig. 1. ${ }^{1} \mathrm{H}$ NMR spectrum of NAP- $\beta C D-I C$ dissolved in d6-DMSO.

The measurement results were adapted to this calibration curve in terms of peak area under curves.

\section{Results and discussion}

Naproxen (NAP) was chosen as a reference drug in this study based on its well-known inclusion complex formation ability with beta-cyclodextrin ( $\beta C D)$ [19,41,42]. The release behavior of NAP after direct incorporation into PCL nanofibers (PCL/NAP) and after NAP- $\beta C D-I C$ formation and incorporation into PCL nanofibers (PCL/NAP- $\beta C D-I C)$ were examined in the present study. The main objective of this study is to get better release profile of NAP from PCL/NAP- $\beta C D-I C$ nanofibers due to higher solubility enhancement of NAP by $\beta C D-I C$ formation.

In the first step, NAP- $\beta C D$-IC was formed by freeze-drying method. The mixing ratios of $1: 4(\mathrm{w} / \mathrm{w})$ was chosen for NAP- $\beta C D$ to provide molar ratio as 1:1.2 for the proper inclusion complex formation. In further steps, several characterization tests were performed to prove the inclusion complex formation. To test the solubility of NAP by $\beta C D$-IC formation, UV-vis analysis was performed. Then, release profiles of NAP from PCL/NAP and PCL/NAP- $\beta C D-I C$ nanofibrous mats in buffer solutions were analyzed by HPLC method.

\subsection{Inclusion complex characterization}

${ }^{1} \mathrm{H}$ NMR study was performed to figure out the molar ratio of NAP- $\beta C D$ and amount of NAP in the inclusion complex. Fig. 1 indicates the ${ }^{1} \mathrm{H}$ NMR spectrum of the NAP- $\beta C D$-IC powder. The molar ratio was calculated by taking the integral of NAP peak at about $1.4 \mathrm{ppm}[43]$ and $\beta C D$ 's characteristic peak at about $4.8 \mathrm{ppm}$ [44] in $d 6$-DMSO system. It was found that, NAP- $\beta C D$-IC have 1:1.2 molar ratio when the integrals of mentioned peaks were proportioned to each other and this ratio is quite well agree with our initial mixing ratio.

Then, we used FTIR spectroscopy to observe the spectral changes and the representative bands of the spectra for the substances before and after IC formation. The FTIR spectra of pure NAP, pure $\beta C D$ and NAP- $\beta C D-I C$ are depicted in Fig. $2 a$. In the FTIR spectrum of NAP, distinct absorption band at $1029 \mathrm{~cm}^{-1}$ corresponds to $\mathrm{C}-\mathrm{O}$ stretching, at $1228 \mathrm{~cm}^{-1}$ corresponds to $-\mathrm{O}-$ stretching, and at $1395 \mathrm{~cm}^{-1}$ corresponds to $\mathrm{CH}_{3}$ bending. Peaks at $1685 \mathrm{~cm}^{-1}$ and
$1729 \mathrm{~cm}^{-1}$ correspond to anti-symmetrical and symmetrical C-O stretching vibrations $[45,46]$. In case of $\beta C D$ spectra, characteristic peaks are appeared at $1029 \mathrm{~cm}^{-1}$, at $1080 \mathrm{~cm}^{-1}$ and $1157 \mathrm{~cm}^{-1}$ due to $\mathrm{C}-\mathrm{O}$ stretch, at $1638 \mathrm{~cm}^{-1}$ due to $\mathrm{H}-\mathrm{OH}$ bending, at $2927 \mathrm{~cm}^{-1}$ due to $\mathrm{C}-\mathrm{H}$ aliphatic stretch, and at $3401 \mathrm{~cm}^{-1}$ due to $\mathrm{O}-\mathrm{H}$ stretching [45-47]. The FTIR spectrum of NAP- $\beta C D-I C$ shows a band at about $1730 \mathrm{~cm}^{-1}$ which comes from NAP with a slight shift which is in an agreement with the literature $[41,42,46]$. Also it was seen that typical peaks of the NAP were suppressed in the NAP- $\beta C D-I C$ spectra which suggested the successful IC formation.

(a)

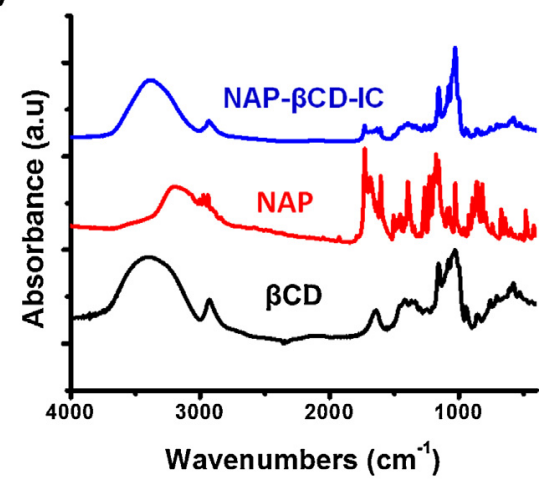

(b)

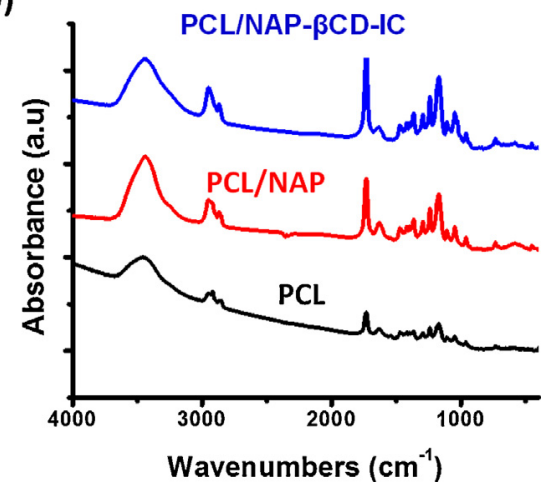

Fig. 2. FTIR spectra of (a) NAP, $\beta-C D$ and NAP- $\beta C D-I C$, and (b) PCL, PCL/NAP and PCL/NAP- $\beta C D-I C$ nanofibers. 

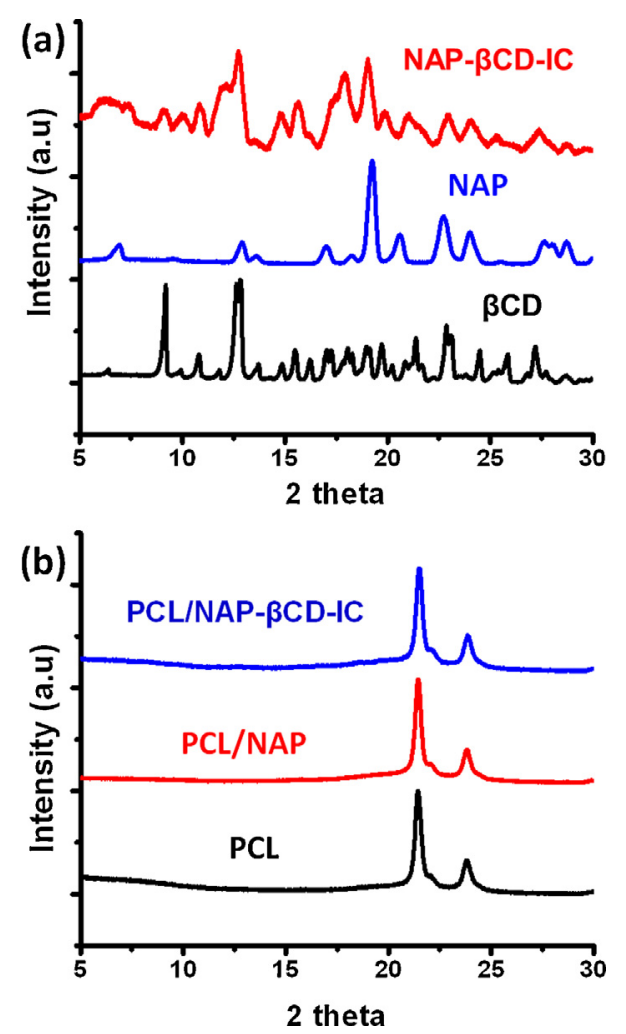

Fig. 3. XRD diffraction patterns of (a) NAP, $\beta-C D$ and NAP- $\beta C D-I C$, and (b) PCL, PCL/NAP and PCL/NAP- $\beta C D-I C$ nanofibers.

The XRD patterns of the pure NAP, pure $\beta C D$ and NAP- $\beta C D-$ IC were recorded to investigate the possible differences in the crystallinity of the structures. As it can be seen from Fig. 3a, for the NAP- $\beta C D-I C$, distinct diffraction peaks for the crystalline NAP were detected in the XRD patterns indicating that some free NAP present in the NAP- $\beta C D-I C$ powder. Also the characteristic peaks of channel-type packing structure at $2 \theta \sim 12^{\circ}, 18^{\circ}$, and $19^{\circ}$ of $\beta C D$ were observed for the NAP- $\beta C D$-IC which shows the successful IC formation of NAP with $\beta C D$ [48].

TGA thermograms of pure NAP, pure $\beta C D$ and NAP- $\beta C D-I C$ are shown in Fig. 4a. TGA thermograms show weight losses below $100^{\circ} \mathrm{C}$ for both $\beta C D$ and NAP- $\beta C D-I C$ due to water loss and main degradation was observed for NAP at $268^{\circ} \mathrm{C}$ and at $350^{\circ} \mathrm{C}$ for $\beta C D$. The water loss was about $11 \%$ for $\beta C D$ while it was around $8 \%$ for NAP- $\beta C D$-IC. The $3 \%$ difference might be attributable to the existence of NAP instead of water in the $\beta C D$ cavity. Other than the initial weight loss, there are two weight losses seen for NAP- $\beta C D-I C$. First one is between $150^{\circ} \mathrm{C}$ and $250^{\circ} \mathrm{C}$ and second one is between $300^{\circ} \mathrm{C}$ and $350^{\circ} \mathrm{C}$ which corresponds to free NAP and IC weight losses that merged with the CD decomposition, respectively. The relative less decomposed amount of uncomplexed free NAP than the initial amount and the higher temperature shift in the NAP- $\beta C D$ part prove the successful formation of NAP- $\beta C D-I C$.

The UV-vis spectroscopy measurements of NAP and NAP- $\beta C D-$ IC solutions were displayed in Fig. 5. As it can be seen from the spectra, the absorption intensity of NAP- $\beta C D-I C$ solution is higher than NAP powder for the same amount of NAP $\left(5 \times 10^{-4} \mathrm{M}\right)$. It is mainly because, the inclusion complexation of NAP with $\beta C D$ enhance the solubility of insoluble drug, NAP, in water medium and leads to higher intensity occurrence in UV-vis-spectra. Thus, the inclusion complexation and the solubility enhancement are also proved by the UV-vis measurements.
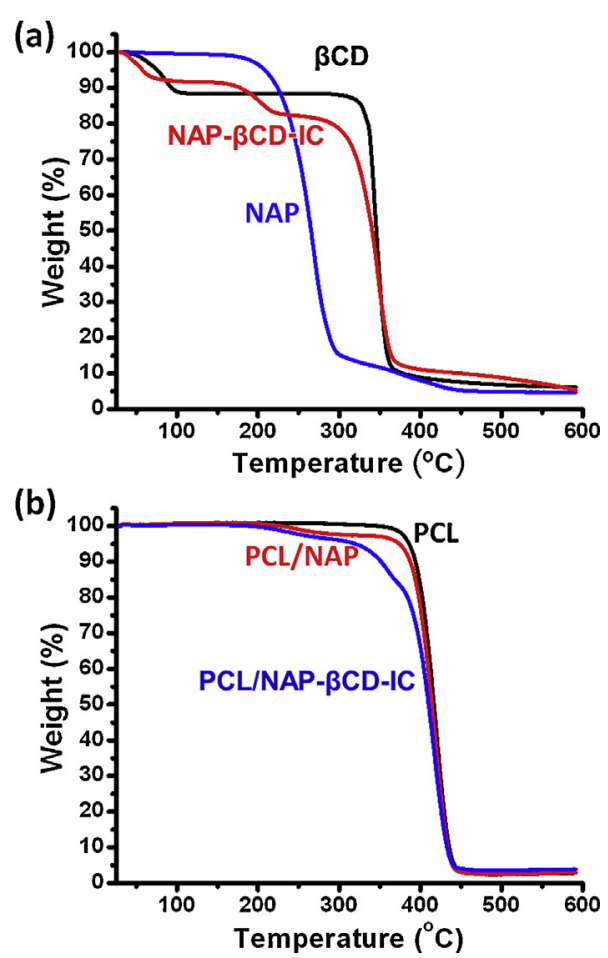

Fig. 4. TGA thermograms of (a) NAP, $\beta-C D$ and NAP- $\beta C D-I C$, and (b) PCL, PCL/NAP and PCL/NAP- $\beta C D-I C$ nanofibers.

\subsection{Characterization of electrospun nanofibers}

Following the characterization studies of NAP- $\beta C D-I C$, PCL polymer matrix was chosen for the production of electrospun nanofibers. Since PCL is water insoluble and biodegradable polymer $[49,50]$, it is thought that the use of PCL nanofibers as a drug delivery system might exhibit convenient release profile for NAP. Following concentration adjustments of the PCL/NAP and PCL/NAP$\beta C D-I C$ blends, electrospinning and characterization studies were performed.

We investigated the morphology of electrospun nanofibers of pure PCL, PCL/NAP and PCL/NAP- $\beta C D-I C$ by SEM imaging. The representative images of SEM micrographs were given in Fig. 6 and fiber diameter distribution data were summarized in Table 1. Uniform, bead free nanofibers with diameter variation were obtained from all three PCL based nanofibrous samples. It is clearly seen in the Fig. $6 c$ that there are IC crystal aggregates accumulated in

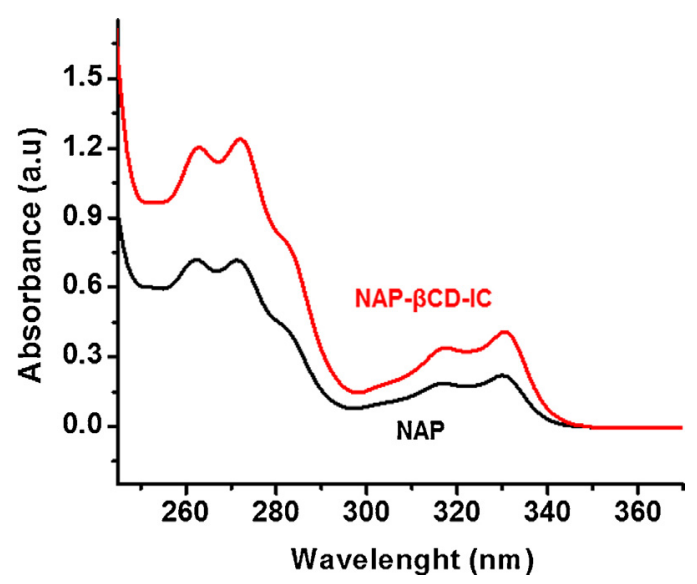

Fig. 5. Solubility analysis of NAP by UV-vis spectroscopy; solubility of pure NAP and solubility of NAP from NAP- $\beta C D-I C$ 
Table 1

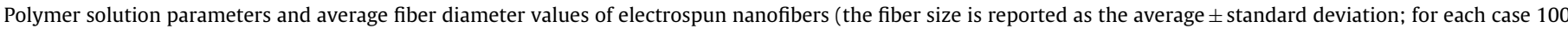
fibers were analyzed).

\begin{tabular}{|c|c|c|c|c|}
\hline & Solvents & Concentrations & Viscosity (Pa s) & Average fiber diameter $(\mathrm{nm})$ \\
\hline PCL & $\operatorname{DMF} / \mathrm{DCM}(3: 1, \mathrm{v} / \mathrm{v})$ & $15 \%(w / v)$ & 0.465 & $336 \pm 100$ \\
\hline PCL/NAP & $\operatorname{DMF} / \mathrm{DCM}(3: 1, \mathrm{v} / \mathrm{v})$ & $15 \%(w / v) / 4 \%(w / w)$ & 0.675 & $361 \pm 152$ \\
\hline PCL/NAP- $\beta C D-I C$ & $\operatorname{DMF} / \mathrm{DCM}(3: 1, \mathrm{v} / \mathrm{v})$ & $15 \%(w / v) / 20 \%(w / w)$ & 0.745 & $389 \pm 167$ \\
\hline
\end{tabular}

the fiber matrix which proves the successful incorporation of NAP$\beta C D$-IC into electrospun PCL nanofibers. It was found out that fiber diameter distributions have good correlation with the viscosity measurement results as can be seen in Table 1. The incorporation of NAP and NAP-BCD-IC into PCL matrix caused viscosity increase in the polymer solutions which finally triggered the formation of nanofibers with larger diameters.

We performed FTIR studies for nanofibers of pure PCL, PCL/NAP and PCL/NAP- $\beta C D-I C$ samples (Fig. 2b). Typical peaks for the PCL are observed at $2949 \mathrm{~cm}^{-1}$ and $2865 \mathrm{~cm}^{-1}$ due to $\mathrm{CH}_{2}$ stretching vibrations, at $1731 \mathrm{~cm}^{-1}$ due to $\mathrm{C}=0$ stretching vibrations, at $1471 \mathrm{~cm}^{-1}$, $1397 \mathrm{~cm}^{-1}$, and $1365 \mathrm{~cm}^{-1}$ due to $\mathrm{CH}_{2}$ bending vibrations. Also $\mathrm{C}-\mathrm{O}$ and $\mathrm{C}-\mathrm{C}$ stretching vibrations at $1293 \mathrm{~cm}^{-1}, \mathrm{C}-\mathrm{O}-\mathrm{C}$ stretching vibrations at $1240 \mathrm{~cm}^{-1}, 1169 \mathrm{~cm}^{-1}, 1108 \mathrm{~cm}^{-1}$, and $1048 \mathrm{~cm}^{-1}$ we detected [51-53]. In FTIR spectra of PCL/NAP nanofibers, the characteristic peaks of PCL mostly exist while none of the characteristic peaks of NAP was observed which is most probably due to the dominant effect of the PCL peaks and the relatively low concentration of NAP in the polymer matrix $(\sim 4 \%, w / w)$. For instance, almost all the peaks in the fingerprint region are quite well fitted with PCL characteristic peaks. However, there is a good indication about the existence of NAP due to some shifted peaks at $2869 \mathrm{~cm}^{-1}$ and $2952 \mathrm{~cm}^{-1}$ while they are located at $2865 \mathrm{~cm}^{-1}$ and $2949 \mathrm{~cm}^{-1}$ in the PCL spectra. The FTIR spectrum of PCL/NAP- $3 C D-I C$ nanofibers has very similar characteristic features with PCL/NAP nanofibers. Again, PCL peaks were oversaturated in the spectra while $\beta C D-I C$ peaks were suppressed, even one of the most distinct peak of $\beta C D$ at $1029 \mathrm{~cm}^{-1}$ is not visible. Although the FTIR spectra did not depict
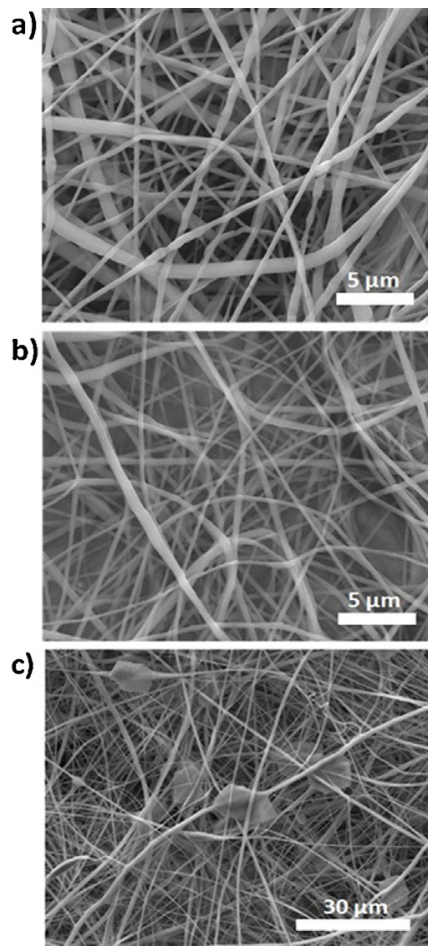

Fig. 6. SEM micrographs of (a) PCL, (b) PCL/NAP and (c) PCL/NAP- $\beta C D-I C$ nanofibers. any interaction between PCL and NAP- $\beta C D$-IC in terms of peak shifts, we cannot rule-out such case. It is due to the fact that the signal from the FTIR spectra originates from two species, namely, interaction and non-interaction of PCL with NAP- $\beta C D-I C$. Also we have only $4 \%$ of NAP in PCL and hence the signal is predominantly coming from PCL.

X-ray diffraction patterns of pure PCL, PCL/NAP and PCL/NAP$\beta C D-I C$ nanofibrous mats are given in Fig. $3 b$. NAP and NAP- $\beta C D-I C$ are crystalline materials, however, the XRD patterns of PCL/NAP and PCL/NAP- $\beta C D-I C$ nanofibrous mats revealed that both NAP$\beta C D-I C$ and NAP transformed into amorphous phase following the incorporation into the PCL nanofibrous matrix.

In TGA thermograms, main degradation of NAP in PCL/NAP nanofibers was found out between $200-250^{\circ} \mathrm{C}$ while for PCL/NAP$\beta C D-I C$ nanofibers, it was found out between $300-375^{\circ} \mathrm{C}$ from the TGA analysis. The TGA thermogram in Fig. $4 \mathrm{~b}$ reveals that PCL nanofibers show main degradation at about $420^{\circ} \mathrm{C}$. By looking TGA thermograms, it is possible to claim the existence of NAP molecules and NAP- $\beta C D-I C$ in the PCL/NAP- $\beta C D-I C$ nanofibers. In both cases, for PCL/NAP and PCL/NAP- $\beta C D$-IC nanofibers, two weight losses were seen after $100^{\circ} \mathrm{C}$ which are independent from water losses.

We studied the release profiles of NAP from PCL/NAP and PCL/NAP- $\beta C D$-IC nanofibers in buffer solution for about $20 \mathrm{~h}$ time period by HPLC. The amount of PCL/NAP and PCL/NAP- $\beta C D-I C$ nanofibers used for the release study was adjusted accordingly in order to have the same amount of NAP in these samples. For both samples, after slight bursting of the drug, slow release behavior was observed for $12 \mathrm{~h}$ period. Then, NAP showed sustained release profiles due to the balanced conditions such as having same diffusion resistance for different time intervals [54]. The release profiles revealed that PCL/NAP- $\beta C D-I C$ nanofibrous system has more than two times higher release rate than PCL/NAP nanofibrous system which is very promising result for the drug delivery purpose (Fig. 7). It also revealed that the formation of NAP- $\beta C D$-IC helped NAP to release from nanofibrous mat much easier which is quite vital in drug delivery applications. As it was proven by our solubility test, CD-IC formation helps NAP to dissolve in water much better which shows its effect on the release behavior of NAP after incorporated into nanofibrous mat. The easy and higher release of drug is important for some specific targets in drug delivery. It is well-known

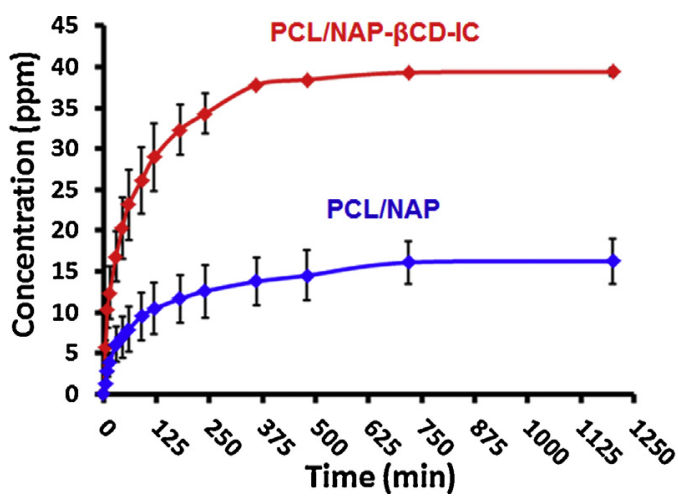

Fig. 7. Release profile of NAP from PCL/NAP and PCL/NAP- $\beta C D-I C$ nanofibrous mats by HPLC with standard deviations (each analysis repeated 3 times, $n=3$ ). 
phenomena that nanofibers can enhance the release behavior of drugs with their high surface area to volume ratio [55,56]. In this study, the positive effect of inclusion complex formation on the release profiles of NAP in addition to nanofiber incorporation has been demonstrated and this may be a promising result for designing novel drug delivery systems.

\section{Conclusions}

The main idea behind this study was to compare the efficiencies of two different delivery systems for the NAP; direct incorporation of NAP and NAP included complex incorporation following IC formation with $\beta C D$ into electrospun PCL nanofibers. Initially, the formation of NAP- $\beta C D-I C$ was studied and then the incorporation of NAP and NAP- $\beta C D-I C$ into PCL nanofibers was performed via electrospinning. The release performance of the NAP was increased more than two times in case of PCL/NAP- $\beta C D$-IC nanofibers when compared with PCL/NAP nanofibers. Thus, it is understood that incorporation of NAP- $\beta C D$-IC in a polymeric nanofibrous system still preserve the improved solubility effect of $\mathrm{CD}-\mathrm{IC}$ on the release rate of NAP and provides a stable environment for it.

\section{Acknowledgment}

State Planning Organization (DPT) of Turkey is acknowledged for the support of UNAM-National Nanotechnology Research Center, Bilkent University. Dr. T. Uyar acknowledges TUBITAKThe Scientific and Technological Research Council of Turkey (project \# 111M459) and EU FP7-PEOPLE-2009_RG Marie Curie-IRG (NANOWEB, PIRG06-GA-2009-256428) and The Turkish Academy of Sciences - Outstanding Young Scientists Award Program (TUBAGEBIP)for funding the research. A. Celebioglu acknowledges TUBITAK-BIDEB for the national Ph.D. study scholarship.

\section{References}

[1] T.M. Allen, P.R. Cullis, Drug delivery systems: entering the mainstream, Science 303 (2004) 1818-1822.

[2] J.L. Frandsen, H. Ghandehari, Recombinant protein-based polymers for advanced drug delivery, Chem. Soc. Rev. 41 (2012) 2696-2706

[3] J.H. Jung, J.H. Lee, J.R. Silverman, G. John, Coordination polymer gels with important environmental and biological applications, Chem. Soc. Rev. 42 (2013) 924-936.

[4] Y. Zhang, J. Zhang, T. Jiang, S. Wang, Inclusion of the poorly water-soluble drug simvastatin in mesocellular foam nanoparticles: drug loading and release properties, Int. J. Pharm. 410 (2011) 118-124.

[5] R. Machin, J.R. Isasi, I. Vélaz, $\beta$-Cyclodextrin hydrogels as potential drug delivery systems, Carbohydr. Polym. 87 (2012) 2024-2030.

[6] J. Kowapradit, A. Apirakaramwong, T. Ngawhirunpat, T. Rojanarata, W. Sajomsang, P. Opanasopit, Methylated N-(4-N,N-dimethylaminobenzyl) chitosan coated liposomes for oral protein drug delivery, Eur. J. Pharm. Sci. 47 (2012) 359-366.

[7] E. D‘Aurizio, P. Sozio, L.S. Cerasa, M. Vacca, L. Brunetti, G. Orlando, A. Chiavaroli, R.J. Kok, W.E. Hennink, A.D. Stefano, Biodegradable microspheres loaded with an anti-parkinson prodrug: an in vivo pharmacokinetic study, Mol. Pharm. 8 (2011) 2408-2415.

[8] J.B. Wolinsky, Y.L. Colson, M.W. Grinstaff, Local drug delivery strategies for cancer treatment: gels, nanoparticles, polymeric films, rods, and wafers, J. Control. Release 159 (2012) 14-26.

[9] S.D. Koker, R. Hoogenboom, B.G.D. Geest, Polymeric multilayer capsules for drug delivery, Chem. Soc. Rev. 41 (2012) 2867-2884.

[10] J.H. Kang, D.H. Oh, Y.-K. Oh, C.S. Yong, H.-G. Choi, Effects of solid carriers on the crystalline properties, dissolution and bioavailability of flurbiprofen in solid self-nanoemulsifying drug delivery system (solid SNEDDS), Eur. J. Pharm. Biopharm. 80 (2012) 289-297.

[11] J.M. Rabanel, V. Aoun, I. Elkin, M. Mokhtar, P. Hildgen, Drug-loaded nanocarriers: passive targeting and crossing of biological barriers, Curr. Med. Chem. 19 (2012) 3070-3102.

[12] L.H. Reddy, J.L. Arias, J. Nicolas, P. Couvreur, Magnetic nanoparticles: design characterization toxicity biocompatibility pharmaceutical biomedical applications, Chem. Rev. 112 (2012) 5818-5878.

[13] T. Loftsson, M.E. Brewster, Cyclodextrins as functional excipients: methods to enhance complexation efficiency, J. Pharm. Sci. 101 (2012) 3019-3032.
[14] F.V.d. Manakker, T. Vermonden, C.F.V. Nostrum, W.E. Hennink, Cyclodextrinbased polymeric materials: synthesis, properties, and pharmaceutical/ biomedical applications, Biomacromolecules 10 (2009) 3157-3175.

[15] W. Gu, C. Wu, J. Chen, Y. Xiao, Nanotechnology in the targeted drug delivery for bone diseases and bone regeneration, Int. J. Nanomed. 8 (2013) 2305-2317.

[16] R. Cheng, F. Meng, C. Deng, H.-A. Klok, Z. Zhong, Dual and multi-stimul responsive polymeric nanoparticles for programmed site-specific drug delivery, Biomaterials 34 (2013) 3647-3657

[17] M.A. Petersen, M.A. Hillmyer, E. Kokkoli, Bioresorbable polymersomes for targeted delivery of cisplatin, Bioconjug. Chem. 24 (2013) 533-543.

[18] N. Sadlej-Sosnowska, L. Kozerski, E. Bednarek, J. Sitkowski, Fluorometric and NMR studies of the naproxen-cyclodextrin inclusion complexes in aqueous solutions, J. Incl. Phenom. Macrocycl. Chem. 37 (2000) 383-394.

[19] A. Banik, P. Gogoi, M.D. Saikia, Interaction of naproxen with $\beta$-cyclodextrin and its derivatives/polymer: experimental and molecular modeling studies, J. Incl. Phenom. Macrocycl. Chem. 72 (2012) 449-458.

[20] M. Cirri, F. Maestrelli, G. Corti, S. Furlanetto, P. Mura, Simultaneous effect of cyclodextrin complexation, $\mathrm{pH}$, and hydrophilic polymers on naproxen solubilization, J. Pharm. Biomed. Anal. 4 (2) (2006) 126-131.

[21] H.L. Ramírez, R. Cao, A. Fragoso, J.J. Torres-Labandeira, A. Dominguez, E.H Schacht, M. Baños, R. Villalonga, Improved anti-inflammatory properties for naproxen with cyclodextrin-grafted polysaccharides, Macromol. Biosci. 6 (2006) 555-561.

[22] S. Tungprapa, I. Jangchud, P. Supaphol, Release characteristics of four model drugs from drug-loaded electrospun cellulose acetate fiber mats, Polymer 48 (2007) 5030-5041.

[23] E.-R. Kenawy, F.I. Abdel-Hay, M.H. El-Newehy, G.E. Wnek, Processing of polymer nanofibers through electrospinning as drug delivery systems, Mater. Chem. Phys. 113 (2009) 296-302

[24] T.J. Sill, H.A.v. Recum, Electrospinning applications in drug delivery and tissue engineering, Biomaterials 29 (2008) 1989-2006.

[25] M.J. Kutyla, L.K. Lambert, N.M. Davies, R.P. McGeary, P.N. Shaw, B.P. Ross, Cyclodextrin-crosslinked poly(acrylic acid): synthesis, physicochemical characterization and controlled release of diflunisal and fluconazole from hydrogels, Int. J. Pharm. 444 (2013) 175-184.

[26] M. Jug, F. Maestrelli, P. Mura, Native and polymeric $\beta$-cyclodextrins in performance improvement of chitosan films aimed for buccal delivery of poorly soluble drugs, J. Incl. Phenom. Macrocycl. Chem. 74 (2012) 87-97.

[27] T. Vigh, T. Horváthová, A. Balogh, P.L. Sóti, G. Drávavölgyi, Z.K. Nagy. G. Marosi, Polymer-free and polyvinylpyrrolidone-based electrospun solid dosage forms for drug dissolution enhancement, Eur. J. Pharm. Sci. 49 (2013) 595-602.

[28] F. Kayaci, O.C.O. Umu, T. Tekinay, T. Uyar, Antibacterial electrospun polylactic acid (PLA) nanofibrous webs incorporating triclosan/cyclodextrin inclusion complexes, J. Agric. Food Chem. 61 (2013) 3901-3908.

[29] F. Kayaci, Y. Ertas, T. Uyar, Enhanced thermal stability of eugenol by cyclodextrin inclusion complex encapsulated in electrospun polymeric nanofibers, J. Agric. Food Chem. 61 (2013) 8156-8165.

[30] F. Kayaci, T. Uyar, Encapsulation of vanillin/cyclodextrin inclusion complex in electrospun polyvinyl alcohol (PVA) nanowebs: prolonged shelf-life and high temperature stability of vanillin, Food Chem. 133 (2012) 641-649.

[31] T. Uyar, Y. Nur, J. Hacaloglu, F. Besenbacher, Electrospinning of functional poly(methyl methacrylate) (PMMA) nanofibers containing cyclodextrinmenthol inclusion complexes, Nanotechnology 20 (2009) 125703.

[32] T. Uyar, J. Hacaloglu, F. Besenbacher, Electrospun polyethylene oxide (PEO) nanofibers containing cyclodextrin inclusion complex, J. Nanosci. Nanotechnol. 5 (2011) 3949-3958.

[33] T. Uyar, J. Hacaloglu, F. Besenbacher, Electrospun polystyrene fibers containing high temperature stable volatile fragrance/flavor facilitated by cyclodextrin inclusion complexes, React. Funct. Polym. 3 (2009) 145-150.

[34] J. Szejtli, Introduction and general overview of cyclodextrin chemistry, Chem. Rev. 98 (1998) 1743-1754.

[35] E.D. Valle, Cyclodextrins and their uses a review, Process Biochem. 39 (2004) 1033-1046.

[36] S.T. Yohe, V.L.M. Herrera, Y.L. Colson, M.W. Grinstaff, 3D superhydrophobic electrospun meshes as reinforcement materials for sustained local drug delivery against colorectal cancer cells, J. Control. Release 162 (2012) 92-101.

[37] X. Li, M.A. Kanjwal, L. Lin, I.S. Chronakis, Electrospun polyvinyl-alcoho nanofibers as oral fast-dissolving delivery system of caffeine and riboflavin, Colloids Surf. B 103 (2013) 182-188.

[38] R. Murugan, S. Ramakrishna, Nano-featured scaffolds for tissue engineering: a review of spinning methodologies, Tissue Eng. 12 (2006) 435-447.

[39] T. Miletic, K. Kyriakos, A. Graovac, S. Ibric, Spray-dried voriconazolecyclodextrin complexes: solubility, dissolution rate and chemical stability, Carbohydr. Polym. 98 (2013) 122-131.

[40] H.S. Mahajan, M.H. Pingale, K.M. Agrawal, Solubility and dissolution enhancement of saquinavir mesylate by inclusion complexation technique, J. Incl. Phenom. Macrocycl. Chem. 76 (2013) 467-472.

[41] J. Blanco, J.L. Vila-Jato, F. Otero, S. Anguiano, Influence of method of preparation on inclusion complexes of naproxen with different cyclodextrins, Drug Dev. Ind. Pharm. 17 (1991) 943-957.

[42] S. Junco, T. Casimiro, N. Ribeiro, M.N.D. Ponte, H.C. Marques, A comparative study of naproxen-beta cyclodextrin complexes prepared by conventiona methods and using supercritical carbon dioxide, J. Incl. Phenom. Macrocycl. Chem. 44 (2002) 117-121. 
[43] E. Marco-Urrea, M. Pérez-Trujillo, P. Blánquez, T. Vicent, G. Caminal, Biodegradation of the analgesic naproxen by trametes versicolor and identification of intermediates using HPLC-DAD-MS and NMR, Bioresour. Technol. 101 (2010) 2159-2166.

[44] S. Divakar, M. Maheswaran, Structural studies on inclusion compounds of $\beta$ cyclodextrin with some substituted phenols, J. Incl. Phenom. Macrocycl. Chem. 27 (1997) 113-126.

[45] H.E. Grandelli, B. Stickle, A. Whittington, E. Kiran, Inclusion complex formation of $\beta$-cyclodextrin and naproxen: a study on exothermic complex formation by differential scanning calorimetry, J. Incl. Phenom. Macrocycl. Chem. 77 (2013) 269-277.

[46] M. Valero, B.I. Perez-Revuelta, L.J. Rodriguez, Effect of PVP K-25 on the formation of the naproxen: $\beta$-cyclodextrin complex, Int. J. Pharm. 253 (2003) 97-110.

[47] L.-F. Chen, O. Shen, J.-P. Shen, D.-T. Shi, T. Chen, H.-R. Yu, Studies and comparison of the liquid adsorption and surface properties of $\alpha$-, $\beta$-, and $\gamma$-cyclodextrins by FTIR and capillary rise method, Colloids Surf. A 411 (2012) 69-73.

[48] A. Harada, M. Okada, J. Li, M. Kamachi, Preparation and characterization of inclusion complexes of poly(propylene glycol) with cyclodextrins, Macromolecules 28 (1995) 8406-8411.

[49] K. Tapan, T.K. Dash, V.B. Konkimalla, Poly- $\varepsilon$-caprolactone based formulations for drug delivery and tissue engineering: a review, J. Control. Release 158 (2012) 15-33.
[50] C. Wu, T.F. Jim, Z. Gan, Y. Zhao, S. Wang, A heterogeneous catalytic kinetics for enzymatic biodegradation of poly( $\varepsilon$-caprolactone) nanoparticles in aqueous solution, Polymer 41 (2000) 3593-3597.

[51] A. Elzubair, C.N. Elias, J.C.M. Suarez, H.P. Lopes, M.V.B. Vieira, The physical characterization of a thermoplastic polymer for endodontic obturation, J. Dent. 34 (2006) 784-789.

[52] S.A. Catledge, W.C. Clem, N. Shrikishen, S. Chowdhury, A.V. Stanishevsky, M. Koopman, Y.K. Vohra, An electrospun triphasic nanofibrous scaffold for bone tissue engineering, Biomed. Mater. 2 (2007) 142-150.

[53] L. Ghasemi-Mobarakeh, M.P. Prabhakaran, M. Morshed, M.H. Nasr-Esfahani, S. Ramakrishna, Bio-functionalized PCL nanofibrous scaffolds for nerve tissue engineering, Mater. Sci. Eng. C 30 (2010) 1129-1136.

[54] X. Sheng, L. Fan, C. He, K. Zhang, X. Mo, H. Wang, Vitamin E-loaded silk fibroin nanofibrous mats fabricated by green process for skin care application, Int. J. Biol. Macromol. 56 (2013) 49-56.

[55] X.-Z. Sun, G.R. Williams, X.-X. Hou, L.-M. Zhu, Electrospun curcumin-loaded fibers with potential biomedical applications, Carbohydr. Polym. 94 (2013) 147-153.

[56] D.W. Chen, Y.-H. Hsu, J.-Y. Liao, S.-J. Liu, J.-K. Chen, S.W.-N. Ueng, Sustainable release of vancomycin, gentamicin and lidocaine from novel electrospun sandwich-structured PLGA/collagen nanofibrous membranes, Int. J. Pharm. 430 (2012). 